\title{
Digestibilidade da dieta, parâmetros ruminais e desempenho de ovinos Santa Inês alimentados com polpa cítrica peletizada e resíduo úmido de cervejaria
}

\author{
Susana Gilaverte ${ }^{1}$, Ivanete Susin ${ }^{1}$, Alexandre Vaz Pires ${ }^{1}$, Evandro Maia Ferreira ${ }^{1}$, Clayton \\ Quirino Mendes $^{1}$, Renato Shinkai Gentil ${ }^{1}$, Marcos Vinicius Biehl ${ }^{1}$, Gustavo Henrique Rodrigues ${ }^{1}$ \\ 1 Universidade de São Paulo, Escola Superior de Agricultura Luiz de Queiroz (ESALQ/USP), Departamento de Zootecnia, Av. Pádua Dias, 11 - \\ Caixa Postal 09 - 13418900 - Piracicaba, SP.
}

RESUMO - Dois experimentos foram realizados com o objetivo de avaliar o efeito da substituição do milho por polpa cítrica peletizada e resíduo úmido de cervejaria sobre a digestibilidade aparente dos nutrientes da dieta, os parâmetros ruminais e o desempenho de ovinos. As dietas foram definidas pela substituição do milho (controle) pela polpa cítrica peletizada ou pela mistura de resíduo úmido de cervejaria e polpa cítrica. No experimento 1, para avaliação do consumo, da digestibilidade aparente dos nutrientes e dos parâmetros ruminais, foram utilizados 12 machos da raça Santa Inês canulados no rúmen, distribuídos em delineamento experimental de blocos completos casualisados, com três dietas e quatro repetições. No experimento 2, para avaliação do desempenho, foram confinadas 48 fêmeas, que foram alimentadas com as mesmas dietas do experimento 1. A substituição do milho pela polpa cítrica peletizada não influenciou o consumo nem a digestibilidade dos nutrientes da dieta, diferente da inclusão de resíduo úmido de cervejaria, que reduziu o consumo e a digestibilidade aparente dos nutrientes, com exceção apenas da FDN, cuja digestibilidade aparente foi similar entre as dietas. A inclusão de resíduo úmido de cervejaria na dieta reduziu as concentrações ruminais de acetato e propionato e aumentou a relação acetato/ propionato e o pH ruminal. Em geral, não há diferença entre a dieta contendo milho e aquela contendo polpa cítrica em substituição total ao milho. A utilização de resíduo úmido de cervejaria, no entanto, reduz o ganho médio diário, o peso corporal final e a eficiência alimentar.

Palavras-chave: borregas, confinamento, consumo, ganho de peso, subproduto

\section{Diet digestibility, ruminal parameters and performance of Santa Ines sheep fed dried citrus pulp and wet brewer grain}

\begin{abstract}
Two experiments were carried out with the objective to determine the effect of replacing corn by dried citrus pulp and wet brewer grain on apparent digestibility of nutrients of the diet, ruminal parameters and performance of sheep. The diets were defined by the replacement of corn (control) by dried citrus pulp or by a mixture of wet brewer grain and citrus pulp. In experiment 1 , for evaluation of intake, apparent digestibility of nutrients and ruminal parameters, 12 Santa Ines ram lambs fitted with canulas in the rumen were assigned to a randomized complete block design with three diets and four replicates. In experiment two, for performance evaluation, 48 ewe lambs were confined and fed the same diets of experiment 1. Replacement of corn by dried citrus pulp did not affect intake or digestibility of nutrients in the diet. However, the inclusion of wet brewer grain reduced intake and apparent digestibility of nutrients, with exception of NDF. Apparent digestibility of NDF was similar among diets. Inclusion of wet brewer grain in the diet decreased ruminal concentration of acetate and propionate and increased acetate/propionate ratio and ruminal $\mathrm{pH}$. In general, there is no difference between the diet containing corn and that containing citrus pulp in total replacement to corn. The use of wet brewer grain, however, reduces average daily gain, final body weight and feed efficiency.
\end{abstract}

Key Words: by-product, feedlot, intake, lambs, weight gain

\section{Introdução}

O mercado nacional de ovinos está em expansão, principalmente em razão do aumento da demanda por carne ovina. Dessa forma, os produtores vêem a atividade como uma alternativa de renda. Dois pontos são fundamentais para viabilizar a criação: aumentar a taxa de desfrute e reduzir os custos da criação. Para isso, o manejo nutricional deve ser adequado, principalmente o das fêmeas, para que o peso de cobertura possa ser alcançado em menor tempo (Hafez, 1988). Nesse sentido, a utilização de subprodutos agroindustriais como substitutos às fontes tradicionais de 
energia (milho e sorgo) em rações de alto nível de concentrado para borregas em confinamento pode proporcionar desempenho favorável e reduzir os custos (Silva et al., 2002).

A polpa cítrica peletizada é um subproduto energético com 79,0\% de nutrientes digestíveis totais (NDT); 7,0\% de proteína bruta (PB); 21,0\% de fibra em detergente neutro (FDN); 2,2\% de extrato etéreo (EE); 7,0\% de matéria mineral (MM); $1,81 \%$ de cálcio e 0,12\% de fósforo (\% MS) (NRC, 2007). Por apresentar alta concentração de pectina, $22,3 \%$ da MS (Bampidis \& Robinson, 2006), e moderado teor de FDN, quando incluída na dieta de ruminantes, a polpa cítrica peletizada estimula a produção de ácido acético em detrimento à produção de ácido lático e diminui a queda do pH ruminal (Wing et al., 1988). Desse modo, pode ser utilizada estrategicamente em substituição ao milho em rações com alto teor de concentrado com intuito de reduzir os riscos de acidose ruminal.

Apesar de já existirem trabalhos com o uso de polpa cítrica peletizada em dietas para ruminantes, poucos incluem avaliação da substituição total do milho pela polpa cítrica em rações com alto nível de concentrado. Além disso, a maioria dos trabalhos existentes apresenta dados pontuais de desempenho, digestibilidade e parâmetros ruminais (Henrique et al., 1998; Leiva et al., 2000; Pinheiro et al., 2000; Henrique et al., 2004; Henrique et al., 2003; Santos et al., 2006), mas não há adequada integração dessas informações.

O resíduo úmido de cervejaria apresenta grande disponibilidade no mercado brasileiro. Segundo Fadel(1999), para cada tonelada de cerveja produzida, são utilizados $150 \mathrm{~kg}$ de grãos de cevada, o que resulta em aproximadamente 36,7 $\mathrm{kg}$ de MS de resíduo de cervejaria. Assim, 25\% do material utilizado no processo industrial da cerveja torna-se resíduo, que precisa de destinação apropriada.

O resíduo úmido de cervejaria apresenta em sua composição 15,2\% de MS; 58,0\% de FDN; 6,8\% de lignina (em \% da FDN); 30,1\% de PB; 10,1\% de EE; 3,9\% de matéria mineral (Tedeschi et al., 2002) e 2,3\% de pectina (Geron et al., 2008). Dessa forma, consiste numa alternativa de alimento proteico e fibroso para utilização em dietas para ruminantes. Em sua composição mineral, apresenta 0,29\% de cálcio e 0,61\% de fósforo na MS (NRC, 2007).

O processo de obtenção da polpa cítrica peletizada resulta num subproduto com elevada concentração de cálcio, devido à necessidade de inclusão de hidróxido de cálcio durante o processo de secagem. Em dietas para ovinos em confinamento, a inclusão em excesso desse subproduto tem reduzido o consumo de MS e o ganho de peso (Rodrigues et al., 2008). O desbalanço na relação cálcio e fósforo em rações com elevada proporção de polpa cítrica pode contribuir para o baixo desempenho. O resíduo úmido de cervejaria, por sua vez, possui alta concentração de fósforo e apresenta-se como alternativa favorável para ajustar a relação cálcio/fósforo de dietas contendo polpa cítrica peletizada.

Este estudo foi realizado com o objetivo de avaliar o efeito da substituição total do milho pela polpa cítrica peletizada em associação ou não ao resíduo úmido de cervejaria em dietas com alta inclusão desses ingredientes sobre a digestibilidade aparente dos nutrientes da dieta e os parâmetros ruminais e desempenho de ovinos em confinamento.

\section{Material e Métodos}

No experimento 1 foram utilizados 12 ovinos da raça Santa Inês, não-castrados, canulados no rúmen, com peso corporal de 48,5 $\pm 11,3 \mathrm{~kg}$ e aproximadamente 11 meses de idade. Os animais foram alojados individualmente em gaiolas metálicas para ensaios de metabolismo com dimensões de $1,30 \times 0,55 \mathrm{~m}$, providas de cocho, bebedouro e sistema para colheita de fezes e urina.

O período experimental teve duração de 18 dias (14 dias para adaptação dos animais às instalações e às dietas experimentais e 4 dias para colheita de dados e de amostras). Os animais foram distribuídos em delineamento experimental de blocos completos casualizados, com três dietas e quatro repetições.

As dietas foram definidas pela substituição total do milho pela polpa cítrica peletizada (46,9\% da MS total) ou pela mistura de polpa cítrica $(30,1 \%)$ e resíduo úmido de cervejaria (30,5\%). As dietas experimentais foram isonitrogenadas ( $18,3 \pm 0,1 \%$ de $\mathrm{PB}$ ) e compostas de $72 \%$ de concentrado e $28 \%$ de volumoso (Tabelas 1 e 2).

O milho e a polpa cítrica peletizada foram grosseiramente moídos, para facilitar a homogeneização, utilizando-se um moedor (Nogueira ${ }^{\circledR}$ DPM - 4, Itapira, Brasil) sem peneira, e misturados aos demais ingredientes concentrados das dietas (farelo de soja, mistura mineral e calcário), com auxílio de um misturador horizontal (Lucato ${ }^{\circledR}$, Limeira, Brasil) com capacidade para $500 \mathrm{~kg}$. Aos ingredientes concentrados foram adicionados ainda $25 \mathrm{mg}$ de monensina sódica por quilograma de ração (\% da matéria natural). O bagaço de cana-de-açúcar foi picado utilizando-se o mesmo moedor.

Todos os dias do período experimental, os alimentos, na forma de mistura completa, foram pesados individualmente em balança eletrônica com precisão de $1 \mathrm{~g}$ (Marte ${ }^{\circledR}$, LC 10, São Paulo, Brasil), homogeneizados manualmente e ofertados à vontade, uma vez ao dia, às 9 h da manhã, permitindo-se sobras de aproximadamente $10 \%$ da 
Tabela 1 - Composição química dos alimentos utilizados nas dietas experimentais (\% da MS)

\begin{tabular}{lccccc}
\hline Composição química & \multicolumn{5}{c}{ Alimento } \\
\cline { 2 - 6 } & Bagaço-de-cana & Farelo de soja & Milho & Polpa cítrica peletizada & Resíduo úmido de cervejaria \\
\hline Matéria seca & 78.8 & 90,5 & 89,0 & 89,5 & 20,7 \\
Matéria orgânica & 95,5 & 93,4 & 99,1 & 93,7 & 95,4 \\
Matéria mineral & 4,5 & 6,6 & 0,9 & 6,3 & 4,6 \\
Proteína bruta & 3,8 & 52,8 & 9,4 & 7,4 & 26,1 \\
Fibra em detergente neutro & 80,3 & 13,1 & 18,4 & 22,2 & 62,1 \\
\hline
\end{tabular}

Tabela 2 - Composição das dietas experimentais (\% da MS)

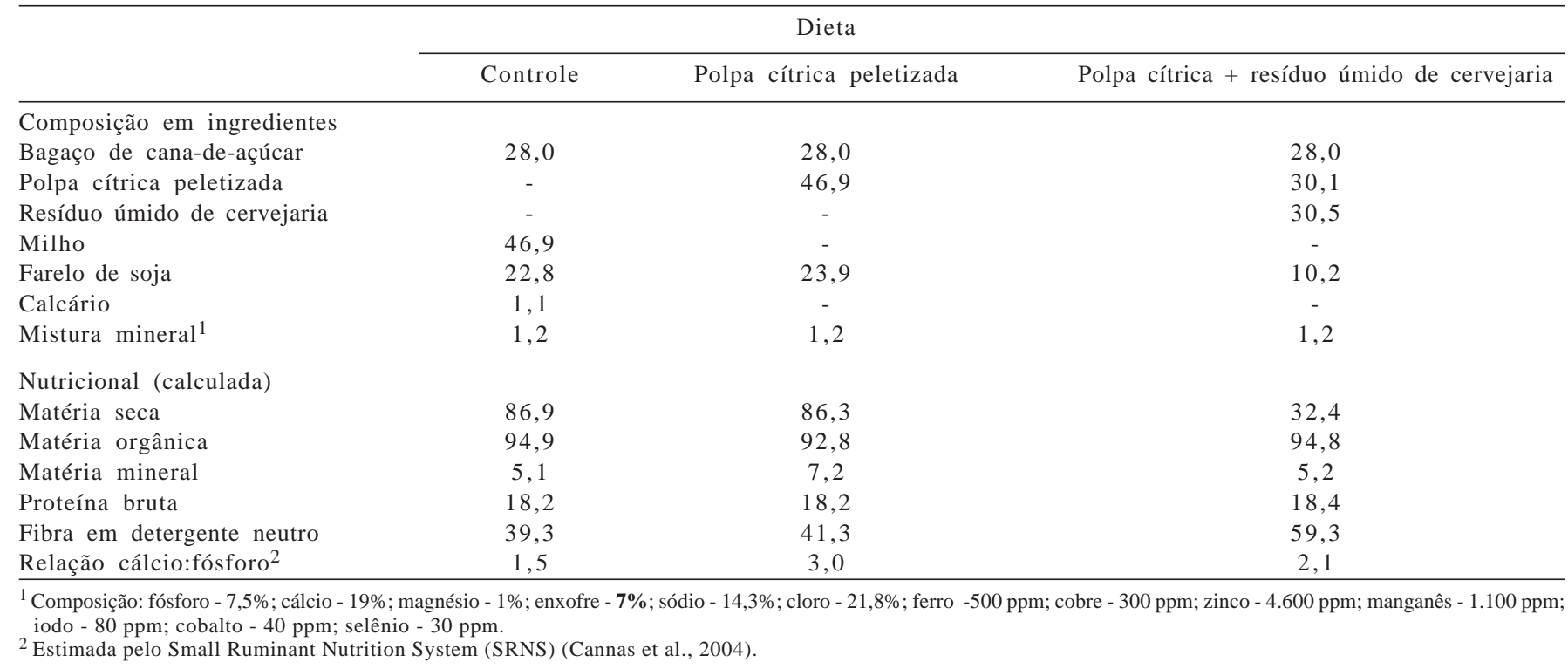

quantidade ofertada. As sobras foram pesadas diariamente para determinar o consumo médio diário de MS. Do $14^{0}$ ao $18^{0}$ dia do período experimental, amostras das dietas experimentais e das sobras de cada animal (10\%) foram coletadas e imediatamente congeladas a $-18^{\circ} \mathrm{C}$.

A coleta total das fezes de cada animal foi realizada por quatro dias seguidos, do $14^{\underline{0}}$ ao $18^{\underline{0}}$ dia do período experimental. Logo após a coleta, as fezes foram pesadas em balança eletrônica com precisão de $1 \mathrm{~g}$ (Marte ${ }^{\circledR}$, LC 10, São Paulo, Brasil), amostradas (10\% do total) e imediatamente congeladas a $-18^{\circ} \mathrm{C}$. Todos os animais foram pesados, no $1^{\circ} \stackrel{0}{ }, 14^{\circ}$ e $18^{\circ}$ dia do período experimental, para obtenção do peso médio.

Amostras do fluido ruminal foram colhidas no 18 o dia do período experimental 0, 2, 4, 6, 8, 10 e 12 horas após o fornecimento das dietas. Em cada horário, uma amostra representativa do conteúdo ruminal de cada animal foi colhida, via cânula, e rapidamente filtrada em tecido de algodão, obtendo-se aproximadamente $200 \mathrm{~mL}$ de fluido ruminal filtrado, que foi utilizado para determinação imediata do pH em potenciômetro digital (Digimed ${ }^{\circledR}$ DM20, São Paulo, Brasil). A fase sólida do conteúdo ruminal que permaneceu no tecido após a filtragem foi devolvida ao rúmen. Após a determinação do $\mathrm{pH}$, retiraram-se duas alíquotas de $25 \mathrm{~mL}$ do fluido ruminal, que foram armazenadas em frascos plásticos contendo 1,25 mL de HCL $6 \mathrm{~N}$ e congeladas a $-18^{\circ} \mathrm{C}$ para análise de ácidos graxos de cadeia curta e N amoniacal.

Depois de descongeladas, as amostras das dietas ofertadas, das sobras e das fezes foram secas em estufa de ventilação forçada a $65^{\circ} \mathrm{C}$ por 72 horas e trituradas em moinho tipo Wiley (Marconi, Piracicaba, Brasil) com peneiras com crivos de 1,0 mm. A matéria seca foi determinada por meio de secagem da amostra em estufa a $105^{\circ} \mathrm{C}$ por 24 horas e a matéria orgânica, por incineração da amostra em mufla a $550^{\circ} \mathrm{C}$ por 4 horas (AOAC, 1990). A concentração de nitrogênio foi determinada por combustão da amostra em aparelho Leco FP528 (Leco Corporation, St. Joseph, MI), conforme a AOAC (1997). A concentração de fibra em detergente neutro (FDN) foi determinada segundo Van Soest et al. (1991), utilizando $\alpha$-amilase termoestável e sulfito de sódio em aparelho Ankom 200 (Ankom Tech. Corp., Fairport, NY), e corrigida para cinzas.

A concentração de nitrogênio amoniacal foi determinada pelo método colorimétrico descrito por Chaney \& Marbach (1962), adaptado para leitura em 
microplaca (BIO - RAD, Hercules, CA), utilizando-se filtro para absorbância de $550 \mathrm{~nm}$.

As amostras de fluido ruminal foram descongeladas e centrifugadas a $15.000 \times \mathrm{g}$ (Sorvall ${ }^{\circledR}$ RC 5B plus, Wilmington, DE) a $4^{\circ} \mathrm{C}$ por 25 minutos e analisadas para determinação dos ácidos graxos de cadeia curta, utilizando-se um cromatógrafo líquido-gasoso (Hewlett Packard 5890 Series II GC), equipado com integrador (Hewlett Packard 3396 Series II Integrator) e injetor automático (Hewlett Packard 6890 Series Injector), conforme descrito por Palmquist \& Conrad (1971). O padrão interno utilizado foi o ácido 2-metilbutírico com acréscimo em cada tubo, para leitura no cromatógrafo, de um volume de $100 \mu \mathrm{L}$ do padrão interno, $800 \mu \mathrm{L}$ da amostra e $200 \mu \mathrm{L}$ de ácido fórmico. Uma mistura de ácidos graxos de cadeia curta com concentração conhecida foi utilizada como padrão externo para calibração do equipamento.

No experimento 2 foram utilizadas 48 fêmeas da raça Santa Inês com peso corporal inicial de 30,4 \pm 3,2 kg e $127 \pm 13$ dias de idade, nascidas entre os meses de setembro a novembro de 2006. Os animais (2/baia) foram confinados em baias cobertas (3,50 $\mathrm{m} \times 1,75 \mathrm{~m})$ com piso de concreto, cocho para fornecimento de dieta $(0,95 \mathrm{~m} \times 0,35 \mathrm{~m})$, bebedouro e saleiros. No início do período experimental, todos os animais receberam por via subcutânea, $1 \mathrm{~mL}$ do antihelmíntico moxidectina (Cydectin ${ }^{\circledR}$ Injetável, Fort Dodge Saúde Animal, Campinas, Brasil) e 0,5 mL de Valléevita ADE (Vallée S/A Produtos Veterinários, Montes Claros, Brasil). Adicionalmente, foram vacinados contra clostridioses com aplicação de $3 \mathrm{~mL}$ de Sintoxan ${ }^{\circledR}$ Polivalente T (Merial Saúde Animal LTDA, Paulínia, Brasil) e contra salmonelose e pasteurelose com aplicação de 2 mL (Laboratório Prado, Curitiba, Brasil).

O período experimental teve duração de 56 dias, divididos em dois subperíodos de 28 dias. Os animais foram distribuídos em delineamento experimental de blocos completos casualizados (oito blocos) de acordo com peso e a idade no início do experimento. As dietas experimentais (Tabela 2) foram formuladas para suprir as exigências de fêmeas ovinas em crescimento com ganho de peso moderado (150 g/dia), conforme recomendações do NRC (2007). O fornecimento das dietas também foi realizado diariamente, como no experimento 1 , e as sobras foram pesadas semanalmente. Amostras de cada porção das dietas ofertadas e das sobras (10\%) foram colhidas e armazenadas a $-18^{\circ} \mathrm{C}$. Depois de descongeladas, as amostras foram processadas e analisadas para determinação da matéria seca, matéria mineral, proteína bruta e fibra em detergente neutro, conforme procedimentos descritos no experimento 1 . Os animais foram pesados nos dias 0,28 e 56 do período experimental, após jejum alimentar de 16 horas.
Todos os dados foram analisados utilizando-se o procedimento Mixed do SAS (2002). Os dados do experimento de desempenho animal (experimento 2) e os dados de consumo de MS e digestibilidade aparente dos nutrientes no trato digestório total (experimento 1) foram analisados conforme o seguinte modelo estatístico: $\mathrm{Y}=\mu+\mathrm{B}_{\mathrm{i}}+\mathrm{T}_{\mathrm{j}}+\mathrm{e}_{\mathrm{ij}}$, em que $\mu=$ média geral; $\mathrm{B}_{\mathrm{i}}=$ efeito de bloco ( $i=1$ a 4$)$ no ensaio de digestibilidade e ( $i=1$ a 8$)$ no experimento de desempenho; $\mathrm{T}_{\mathrm{j}}=$ efeito de dieta $(\mathrm{j}=1 \mathrm{a} 3)$; e $e_{i j}=$ erro residual.

Os parâmetros de fermentação ruminal foram analisados como medidas repetidas no tempo, conforme o modelo estatístico que segue: $\mathrm{Y}=\mu+\mathrm{B}_{\mathrm{i}}+\mathrm{T}_{\mathrm{j}}+\mathrm{H}_{\mathrm{k}}+\mathrm{T}_{\mathrm{j}} \times \mathrm{H}_{\mathrm{k}}+\mathrm{e}_{\mathrm{ijk}}$, em que $\mu=$ média geral; $B_{i}=$ efeito de bloco ( $\left.\mathrm{i}=1 \mathrm{a} 4\right) ; \mathrm{T}_{\mathrm{j}}=$ efeito de dieta ( $\mathrm{j}=1$ a 3); $\mathrm{H}_{\mathrm{k}}$ = efeito de horas após a alimentação; $\mathrm{T}_{\mathrm{j}} \times \mathrm{H}_{\mathrm{k}}=$ interação entre dieta e horas após alimentação; e $\mathrm{e}_{\mathrm{ijk}}=$ erro residual. A estrutura de covariância que melhor se ajustou ao conjuto de dados dos parâmetros ruminais foi a "Autoregressive". Todas as médias dos tratamentos foram obtidas pelo comando LSMEANS e o teste Tukey foi aplicado quando detectado efeito das dietas $(\mathrm{P}<0,05)$.

\section{Resultados e Discussão}

No experimento 1, os consumos de matéria seca, matéria orgânica, proteína bruta fibra insolúvel em detergente neutro, expressos em $\mathrm{kg} / \mathrm{dia}$ e em $\mathrm{g} / \mathrm{kg}$ de $\mathrm{PC}^{0,75}$, não se alteraram $(\mathrm{P}>0,05)$ com a substituição do milho pela polpa cítrica, entretanto, a substituição do milho pela mistura de polpa cítrica e resíduo úmido de cervejaria reduziu $(\mathrm{P}<0,05)$ consistentemente o consumo desses nutrientes em relação ao observado com o fornecimento das dietas contendo milho ou polpa cítrica. Apenas o consumo de FDN não diferiu $(\mathrm{P}>0,05)$ entre as dietas contendo polpa cítrica (Tabela 3).

Os resultados obtidos com a substituição do milho pela polpa cítrica estão de acordo com os reportados por Prado et al. (2000) e Henrique et al. (2004), que também não notaram efeito da substituição parcial do milho pela polpa cítrica sobre o consumo de matéria seca, o que reforça a ideia de que a polpa cítrica tem aceitação semelhante à do milho pelos animais.

O consumo de matéria seca é determinado principalmente pelo enchimento físico do rúmen no caso de dietas com alto teor de forragem ou por mecanismos quimiostáticos em dietas com alta densidade energética (Waldo, 1986). Nesta pesquisa, como as dietas continham alto teor de concentrado (Tabela 2), o consumo de MS semelhante entre as dietas contendo milho e polpa cítrica provavelmente foi determinado primeiramente por mecanismos quimiostáticos, 
visto que o NDT dessas dietas obtido a partir da digestibilidade da matéria orgânica (Lofgreen, 1953; Crampton et al., 1957) foi semelhante (75,8\% e 78,8\% para as dietas contendo milho e polpa cítrica, respectivamente).

A inclusão do resíduo úmido de cervejaria na dieta reduziu $(\mathrm{P}<0,05)$ em $54,2 \%$ o consumo de MS em relação à dieta contendo milho e $43,2 \%$ em relação à dieta contendo polpa cítrica. É possível que a alta umidade da dieta contendo resíduo úmido de cervejaria (32,4\% de MS), em comp aração às dietas contendo milho (86,9\% de MS) e polpa cítrica (86,3\% de MS), e a maior concentração de FDN nas dietas contendo resíduo úmido de cervejaria (Tabela 1) tenham provocado limitação física ao aumento no consumo de MS.

Assim como verificado no experimento (Tabela 2), Brochier \& Carvalho (2008) substituíram o farelo de soja (28,62\% da MS) e o milho desintegrado (30,42\% da MS) em 0, 25, 50, 75 e 100\% pelo resíduo úmido de cervejaria em rações para cordeiros e verificaram redução no consumo de MS a partir do nível de 50\% de substituição (30\% de resíduo de cervejaria na MS).
A substituição do milho pela polpa cítrica não alterou $(\mathrm{P}>0,05)$ a digestibilidade aparente de MS, MO, PB e FDN, ao passo que a inclusão de resíduo úmido de cervejaria na dieta reduziu $(\mathrm{P}<0,05)$ a digestibilidade da $\mathrm{MS}$, $\mathrm{MO}$ e $\mathrm{PB}$ em relação à dieta contendo milho. A digestibilidade da FDN, no entanto, não diferiu $(\mathrm{P}>0,05)$ entre estas dietas, embora em comparação à dieta contendo polpa cítrica a inclusão do resíduo úmido de cervejaria tenha promovido redução na digestibilidade de todos os nutrientes avaliados (Tabela 4).

De acordo com NRC (2007), o teor de NDT do milho e da polpa cítrica é de 88 e $79 \%$, respectivamente. Considerando o valor de digestibilidade da matéria orgânica como igual ao de NDT (Lofgreen, 1953; Crampton et al., 1957), os valores de NDT para as dietas contendo milho e polpa cítrica foram de 75,8 e 78,8\%, respectivamente, e indicam que o valor de NDT tabelado para a polpa cítrica, relativamente ao do milho, é subestimado pelo NRC (2007). Em estudos com bovinos de corte, também tem sido verificada similar digestibilidade da $\mathrm{MO}$ em rações contendo milho ou polpa cítrica (Henrique et al., 2003).

Tabela 3 - Consumo de nutrientes em ovinos alimentados com dietas contendo polpa cítrica peletizada ou resíduo úmido de cervejaria em substituição ao milho

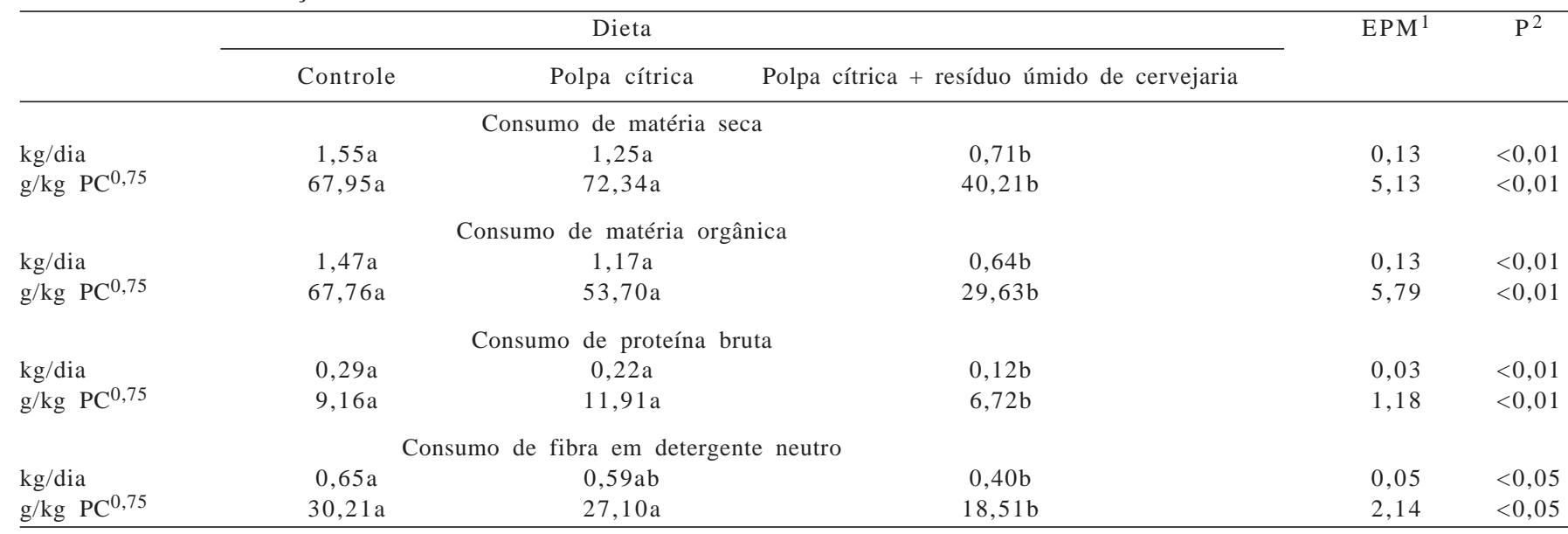

${ }^{1}$ Erro-padrão da média.

2 Probabilidade de existir efeito significativo das dietas.

Tabela 4 - Digestibilidade aparente dos nutrientes no trato digestório total de ovinos alimentados com polpa cítrica peletizada ou resíduo de cervejaria em substituição ao milho na dieta

\begin{tabular}{|c|c|c|c|c|c|}
\hline & \multicolumn{3}{|c|}{ Dieta } & $\mathrm{EPM}^{1}$ & $\mathrm{P}^{2}$ \\
\hline \multicolumn{6}{|l|}{ Digestibilidade, \% } \\
\hline Matéria orgânica & $77,80 a$ & $80,47 a$ & $58,93 b$ & 3,31 & $<0,01$ \\
\hline Proteína bruta & $82,35 a$ & $80,52 a$ & $74,18 b$ & 1,50 & $<0,05$ \\
\hline Fibra em detergente neutro & $64,61 \mathrm{ab}$ & $76,39 a$ & $53,27 b$ & 3,41 & $<0,05$ \\
\hline
\end{tabular}

\footnotetext{
${ }^{1}$ Erro-padrão da média.
}

${ }^{2}$ Probabilidade de existir efeito significativo das dietas. 
A menor $(\mathrm{P}<0,05)$ digestibilidade da $\mathrm{PB}$ da dieta contendo resíduo úmido de cervejaria pode ser explicada em parte pela maior inclusão de farelo de soja nas dietas contendo milho e polpa cítrica (22,8 e $23,9 \%$ da MS, respectivamente) em relação à dieta contendo resíduo úmido de cervejaria (10,2\% da MS), visto que a digestibilidade da fração nitrogenada do resíduo úmido de cervejaria é inferior à do farelo de soja (Armentano et al., 1986). A concentração de PB do resíduo úmido de cervejaria (26,1\% da MS) é superior à do milho (9,4\% da MS) e da polpa cítrica peletizada (7,4\% da MS) (Tabela 1$)$, o que justifica a menor inclusão de farelo de soja nas rações contendo este ingrediente.

Adicionalmente, durante a produção do resíduo úmido de cervejaria, a maior parte das proteínas solúveis, albuminas e globulinas, é removida ou fermentada, o que também pode reduzir a digestibilidade da PB desse ingrediente em comparação ao milho e à polpa cítrica peletizada. Suportando essa hipótese, a concentração de nitrogênio solúvel (\% PB) do resíduo úmido de cervejaria (8\% da PB) é inferior à do milho (17,8\% da PB) e da polpa cítrica (27\% da $\mathrm{PB})$, ao passo que a concentração de nitrogênio ligado à FDN (fração de lenta digestão) é maior no resíduo úmido de cervejaria (62,8\% da PB) que no milho (6,8\% da PB) e na polpa cítrica (21,1\% da PB). Finalmente, a concentração de nitrogênio ligado à FDA (fração indisponível) no resíduo úmido de cervejaria (11,7\% da PB) é superior à do milho (2,3\% da PB), embora seja ligeiramente inferior à da polpa cítrica peletizada $(16,34 \%$ da PB) (Tedeschi et al., 2002). Em conjunto, esses dados são consistentes com a menor digestibilidade da PB das dietas contendo resíduo úmido de cervejaria.
A menor $(\mathrm{P}<0,01)$ digestibilidade da FDN da dieta contendo resíduo úmido de cervejaria em comparação à da dieta contendo polpa cítrica peletizada pode ser explicada pela maior concentração de lignina do resíduo úmido de cervejaria (4,3\% da MS) (Firkins et al., 2002) em relação à polpa cítrica peletizada (1,0\% da MS) (NRC, 2007). Por sua vez, o milho apresenta concentração intermediária de lignina (2,9\% da MS) (NRC, 2007) em comparação aos demais ingredientes e isso explica a digestibilidade semelhante verificada na comparação entre as dietas contendo milho ou polpa cítrica peletizada e entre as dietas contendo milho ou resíduo úmido de cervejaria.

Para todas as variáveis de parâmetros ruminais avaliadas, não se verificou efeito $(P>0,05)$ de interação entre dieta e tempo após fornecimento (Tabela 5). A concentração ruminal de acetato não diferiu $(\mathrm{P}>0,05)$ entre as dietas contendo milho ou polpa cítrica peletizada, mas reduziu $(\mathrm{P}<0,01)$ com a utilização do resíduo úmido de cervejaria. Ao mesmo tempo, a proporção molar desse ácido graxo (\% em relação à concentração total de ácidos graxos de cadeia curta) foi maior nas dietas contendo resíduo úmido de cervejaria e naquela contendo polpa cítrica peletizada em comparação à dieta controle, com milho, e isso evidencia que a menor concentração ruminal de acetato verificada com o uso de resíduo úmido de cervejaria foi provocada pela menor produção total de ácidos graxos de cadeia curta também verificada para essa dieta, que, por sua vez, foi determinada pelo menor consumo de MO digestível pelos animais alimentados com as dietas contendo resíduo úmido de cervejaria, tendo em vista o menor consumo de matéria orgânica (Tabela 3) e a menor digestibilidade aparente desse nutriente (Tabela 4).

Tabela 5 - Parâmetros ruminais de ovinos alimentados com dietas contendo polpa cítrica peletizada e resíduo úmido de cervejaria em substituição ao milho

\begin{tabular}{|c|c|c|c|c|c|c|c|}
\hline \multirow[t]{2}{*}{ Item } & \multicolumn{3}{|c|}{ Dieta } & \multirow[t]{2}{*}{ EPM } & \multirow[t]{2}{*}{$\mathrm{P}$} & \multirow[t]{2}{*}{$\mathrm{H}$} & \multirow[t]{2}{*}{$\mathrm{T} * \mathrm{H}$} \\
\hline & Controle & $\begin{array}{l}\text { Polpa cítrica } \\
\text { peletizada }\end{array}$ & $\begin{array}{l}\text { Polpa cítrica }+ \\
\text { resíduo úmido de cervejaria }\end{array}$ & & & & \\
\hline Ácidos graxos de cadeia curta totais (mM) & 71,08 & 61,37 & 40,77 & 3,23 & 0,07 & 0,09 & 0,76 \\
\hline Acetato & $40,08 a$ & $38,86 a$ & $26,90 b$ & 1,73 & $<0,01$ & 0,13 & 0,99 \\
\hline Propionato & $18,90 \mathrm{a}$ & $13,86 a b$ & $8,56 b$ & 1,18 & $<0,05$ & $<0,05$ & 0,40 \\
\hline Butirato & 8,13 & 6,09 & 3,81 & 0,44 & 0,07 & 0,09 & 0,94 \\
\hline Relação acetato:propionato & $2,50 \mathrm{~b}$ & $2,92 \mathrm{ab}$ & $3,21 \mathrm{a}$ & 0,09 & $<0,01$ & $<0,05$ & 0,78 \\
\hline \multicolumn{8}{|l|}{ Molar (\%) } \\
\hline Acetato & $57,91 b$ & $64,01 \mathrm{a}$ & $65,78 a$ & 0,80 & $<0,01$ & 0,56 & 0,39 \\
\hline Propionato & $25,42 \mathrm{a}$ & $22,88 \mathrm{ab}$ & $20,90 b$ & 0,67 & $<0,05$ & 0,06 & 0,77 \\
\hline Butirato & $11,16 \mathrm{a}$ & $9,59 b$ & $9,21 \mathrm{~b}$ & 0,25 & $<0,01$ & 0,41 & 0,81 \\
\hline pH ruminal & $6,14 \mathrm{~b}$ & $6,19 b$ & $6,58 a$ & 0,06 & $<0,01$ & $<0,01$ & 0,76 \\
\hline $\mathrm{NH}_{3}$ ruminal & $19,33 a$ & $13,11 b$ & $10,82 b$ & 0,92 & $<0,01$ & $<0,01$ & 0,76 \\
\hline
\end{tabular}

EPM = erro-padrão da média.

$\mathrm{P}=$ probabilidade de existir efeito significativo das dietas

$\mathrm{H}=$ efeito do tempo após a alimentação.

$\mathrm{T}^{*} \mathrm{H}=$ efeito da interação entre dieta e tempo alimentação. 
A inclusão de resíduo úmido de cervejaria na dieta reduziu $(\mathrm{P}<0,05)$ a concentração ruminal de propionato em comparação à dieta contendo milho, todavia não houve diferença $(\mathrm{P}>0,05)$ entre a dieta contendo polpa cítrica peletizada e as demais. Resultado semelhante foi verificado para a proporção molar de propionato. A alta concentração de amido do milho (60\% da MS; NRC, 2007), por apresentar alta taxa de degradação ruminal, e o padrão de fermentação, que conduz a maior produção de propionato, justificam esses resultados (Poore et al., 1993).

A concentração ruminal de butirato não foi afetada $(\mathrm{P}>0,05)$ pelas dietas, embora tenha sido verificada maior $(\mathrm{P}<0,05)$ proporção molar desse ácido graxo na dieta contendo milho em relação às contendo polpa cítrica peletizada ou resíduo úmido de cervejaria, que, por sua vez, não diferiram ( $\mathrm{P}>0,05)$.

De modo contrário ao verificado para a proporção molar de propionato, a dieta contendo resíduo úmido de cervejaria apresentou maior $(\mathrm{P}<0,05)$ relação acetato/propionato em comparação àquela contendo milho, mas não houve diferença $(\mathrm{P}>0,05)$ entre a dieta contendo polpa cítrica peletizada e as demais. Como já relatado, a maior concentração ruminal de propionato em relação ao acetato na dieta contendo milho deve-se ao alto teor de amido do milho. O resíduo úmido de cervejaria, no entanto, apresenta teor de amido inferior ao do milho e alto teor de FDN (Tabela 1), o que favoreceu a maior concentração ruminal de acetato em relação à de propionato, uma vez que o acetato é o mais importante ácido graxo de cadeia curta produzido durante a fermentação da fibra (Firkins et al., 2006).

Os animais alimentados com as dietas contendo resíduo úmido de cervejaria apresentaram maior $(\mathrm{P}<0,05) \mathrm{pH}$ ruminal, enquanto entre as dietas contendo milho ou polpa cítrica peletizada não houve diferença $(\mathrm{P}>0,05)$ (Tabela 5). As menores variações diárias no $\mathrm{pH}$ ruminal foram observadas nos animais alimentados com as dietas contendo resíduo úmido de cervejaria $(6,58 \pm 0,26)$ em relação àquelas contendo polpa cítrica peletizada $(6,19 \pm 0,43)$ ou milho $(6,14 \pm 0,46)$ (Figura 1). Os valores mínimos de $\mathrm{pH}$ ao longo do período de observação foram de 5,80 às 10 horas; 5,88 às 10 horas e 6,38 às 12 horas após alimentação para as dietas controle, com polpa cítrica peletizada e com polpa cítrica peletizada + resíduo úmido de cervejaria, respectivamente. Outra informação importante é que, em todos os horários de observação, não houve diferença $(\mathrm{P}>0,05)$ nos valores de $\mathrm{pH}$ ruminal entre as dietas contendo polpa cítrica peletizada e milho. Por outro lado, o pH ruminal dos animais alimentados com as dietas contendo resíduo úmido de cervejaria foi superior ao daqueles alimentados com milho ou polpa cítrica peletizada a partir de 4 horas após o fornecimento das dietas. Resultados similares foram verificados por Davis et al. (1983) ao incluírem resíduo úmido de cervejaria nos níveis de 20, 30 e 40\% da dieta.

A maior relação acetato/propionato e a menor concentração ruminal total de ácidos graxos de cadeia curta obtidas com a dieta contendo resíduo úmido de cervejaria (Tabela 5) explica parcialmente esses resultados. Além disso, o teor de FDN da dieta contendo resíduo úmido de cervejaria (59,3\% da MS) foi superior ao das dietas contendo milho (39,3\% da MS) e polpa cítrica peletizada (41,3\% da MS) (Tabela 2), em virtude da maior concentração de FDN do resíduo úmido cervejaria (62,1\% da MS) em comparação à do milho (18,4\% da MS) e da polpa cítrica peletizada (22,2\% da MS) (Tabela 1). Esses valores explicam as alterações na concentração de ácidos graxos de cadeia curta no rúmen e o maior $\mathrm{pH}$ ruminal dos animais alimentados com a dieta contendo resíduo úmido de cervejaria.

A inclusão de resíduo úmido de cervejaria na dieta reduziu $(P<0,05)$ a concentração ruminal de nitrogênio amoniacal, em comparação às demais dietas, o que pode ser atribuído à menor digestibilidade da PB (Tabela 4). Em contrapartida, a inclusão de polpa cítrica peletizada na dieta, mesmo não tendo influenciado a digestibilidade aparente da PB no trato digestório total (Tabela 4), promoveu redução $(P<0,05)$ na concentração ruminal de nitrogênio amoniacal, o que sugere redução na taxa de degradação ruminal da PB com o uso de polpa cítrica peletizada na dieta. É importante ressaltar que, apesar de os subprodutos (polpa cítrica peletizada e resíduo úmido de cervejaria) terem reduzido a concentração de nitrogênio amoniacal, sua concentração em todas as rações foi superior à quantidade mínima de $5 \mathrm{mg} / \mathrm{dL}$ necessária para adequado crescimento microbiano (Leng \& Nolan, 1984).

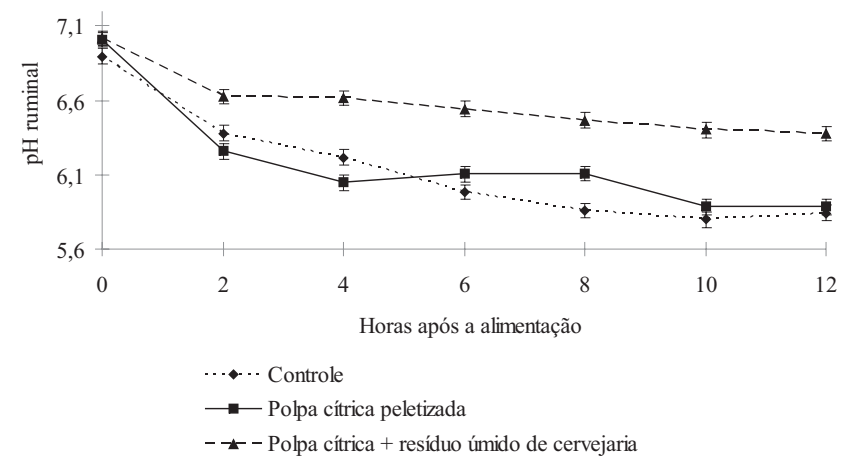

Figura 1 - pH ruminal de ovinos alimentados com dietas contendo polpa cítrica peletizada ou mistura de polpa cítrica peletizada e resíduo úmido de cervejaria em substituição do milho. 
De modo semelhante ao verificado no experimento 1 , no experimento 2, o consumo de MS (kg/dia, \% PV, g/kg de PC ${ }^{0,75}$ ) não se alterou $(\mathrm{P}>0,05)$ com a substituição do milho pela polpa cítrica peletizada, entretanto reduziu $(\mathrm{P}<0,05)$ com a inclusão de resíduo úmido de cervejaria (Tabela 6).

$\mathrm{O}$ ganho médio diário (GMD), peso corporal final e eficiência alimentar também não diferiram $(P>0,05)$ com a substituição do milho pela polpa cítrica peletizada. Os principais fatores que explicam esses resultados são o consumo de MS e a digestibilidade aparente de todos os nutrientes avaliados, que foram semelhantes entre as rações contendo milho ou polpa cítrica peletizada (Tabelas 3 e 4). Por sua vez, o menor ganho médio diário, peso corporal final e eficiência alimentar verificados $(\mathrm{P}<0,05)$ com a inclusão de resíduo úmido de cervejaria na dieta foram ocasionados pelo fato de esse subproduto na dieta ter reduzido severamente o consumo de MS e a digestibilidade aparente dos nutrientes (Tabelas 3 e 4).
Em experimento com cordeiros, Brochier \& Carvalho (2008) substituíram 0, 25, 50, 75 e 100\% do concentrado da dieta (60\% da MS) por resíduo úmido de cervejaria e também verificaram redução linear no ganho médio diário. Rodrigues et al. (2008) substituíram o milho pela polpa cítrica peletizada em dietas para cordeiros confinados e verificaram resposta quadrática no ganho médio diário. Neste experimento, a polpa cítrica peletizada foi incluída em até $46,9 \%$ da MS em susbtituição total ao milho e não prejudicou o ganho médio diário. Rodrigues et al. (2008) atribuíram a redução no ganho médio diário observado, a partir do nível de 46,1\% polpa cítrica peletizada na dieta, à diminuição no consumo de MS também observada a partir desse nível de substituição. Nas dietas com maior nível de polpa cítrica peletizada, Rodrigues et al. (2008) adicionaram também monoaminofosfato, o que possivelmente reduziu a aceitação das dietas pelos animais.

Tabela 6 - Desempenho de ovinos alimentados com dietas contendo polpa cítrica peletizada e resíduo úmido de cervejaria em substituição ao milho

\begin{tabular}{|c|c|c|c|c|c|}
\hline \multirow[t]{2}{*}{ Item } & \multicolumn{3}{|c|}{ Dieta } & \multirow[t]{2}{*}{$\mathrm{EPM}^{1}$} & \multirow[t]{2}{*}{$\mathrm{P}^{2}$} \\
\hline & Controle & $\begin{array}{l}\text { polpa cítrica } \\
\text { peletizada }\end{array}$ & $\begin{array}{l}\text { Polpa cítrica peletizada }+ \\
\text { resíduo úmido de cervejaria }\end{array}$ & & \\
\hline Peso final, kg & $35,5 a$ & $34,6 a$ & $29,4 b$ & 0,59 & $<0,01$ \\
\hline CMS, kg/dia & $0,88 a$ & $0,89 a$ & $0,51 b$ & 0,03 & $<0,01$ \\
\hline$\% \mathrm{PV}$ & $2,65 a$ & $2,74 a$ & $1,67 b$ & 0,06 & $<0,01$ \\
\hline Eficiência alimentar, g de ganho/kg MS & $187,5 \mathrm{a}$ & $160,6 a$ & $17,0 \mathrm{~b}$ & 0,01 & $<0,01$ \\
\hline
\end{tabular}

${ }^{1}$ Erro-padrão da média.

${ }^{2}$ Probabilidade de existir efeito significativo das dietas.

\section{Conclusões}

A polpa cítrica peletizada pode substituir totalmente $\mathrm{o}$ milho em dietas para ovinos em crescimento, pois essa substituição não afeta a digestibilidade aparente dos nutrientes nem o desempenho animal. Em contrapartida, o resíduo úmido de cervejaria não deve ser incluído em dietas para ovinos em crescimento, pois reduz o ganho médio diário dos animais.

\section{Referências}

ARMENTANO, L.E.; HERRINGTON, T.A.; POLAN, C.E. et al. Ruminal degradation of dried brewers grains, wet brewers grains, and soybean meal. Journal of Dairy Science, v.69, n.8, p.2124-2133, 1986.

ASSOCIATION OF OFFICIAL ANALYTICAL CHEMISTIS AOAC. Official methods of analysis. 15.ed. Arlington: AOAC International, 1990. 1117p.
ASSOCIATION OF OFFICIAL ANALYTICAL CHEMISTIS AOAC. Official methods of analysis. 16.ed. Gaithersburg: AOAC International, 1997. MD.

BAMPIDIS, V.A.; ROBINSON, P.H. Citrus by-products as ruminant feed: a review. Animal Feed Science and Technology, v.128, n.3/4, p.175-217, 2006.

BROCHIER, M.A.; CARVALHO, S. Consumo, ganho de peso e análise econômica da terminação de cordeiros em confinamento com dietas contendo diferentes proporções de resíduo úmido de cervejaria. Arquivo Brasileiro de Medicina Veterinária e Zootecnia, v.60, n.5, p.1205-1212, 2008.

CANNAS, A.; TEDESCHI, L.O.; FOX, D.G. et al. A mechanistic model for predicting the nutrient requirements and feed biological value for sheep. Journal of Animal Science, v.82, n.1, p.149-169, 2004.

CHANEY, A.L.; MARBACH, E.P. Modified reagents for determination of urea and ammonia. Clinical Chemistry, v.8, n.2, p.130-146, 1962.

CRAMPTON, E.W.; LLOYD, F.E.; MACKAY, V.G. The calorie value of TDN. Journal of Animal Science, v.16, n.3, p.541-545, 1957.

DAVIS, C.L.; GRENAWALT, D.A.; McGOY, G.C. Feeding value of pressed brewers' grains for lactating dairy cows. Journal of Dairy Science, v.66, n.1, p.73-79, 1983. 
FADEL, J.G. Quantitative analyses of selected plant by product feedstuffs, a global perspective. Animal Feed Science and Technology, v.79, p.255-268, 1999.

FIRKINS, J.L.; HARVATINE, D.I.; SYLVESTER, J.T. et al. Lactation performance by dairy cows fed wet brewers grains or whole cottonseed to replace forage. Journal of Dairy Science, v.85, n.10, p.2662-2668, 2002.

FIRKINS, J.L.; HRISTOV, A.N.; HALL, M.B. et al. Integration of ruminal metabolism in dairy cattle. Journal of Dairy Science, v.89, n.1, E31-E51, 2006 (E. Suppl.).

GERON, L.J.; ZEOULA, L.M.; ERKEL, J.A. et al. Coeficiente de digestibilidade e características ruminais de bovinos alimentados com rações contendo resíduo de cervejaria úmido fermentado. Revista Brasileira de Zootecnia, v.37, n.9, p.1685-1695, 2008.

HAFEZ, E.S.E. Reprodução animal. 4.ed. Zaragoza: Acríbia, 1988. $720 \mathrm{p}$.

HENRIQUE, W.; LEME, P.R.; LANNA, D.P.D. et al. Substituição de amido por pectina em rações com diferentes níveis de concentrado. 1. Desempenho animal e características da carcaça. Revista Brasileira de Zootecnia, v.27, n.6, p.1206-1211, 1998.

HENRIQUE, W.; SAMPAIO, A.A.M.; LEME, P.R. et al. Desempenho e características de carcaça de tourinhos Santa Gertrudes confinados recebendo rações com alto concentrado e níveis crescentes de polpa cítrica peletizada. Revista Brasileira de Zootecnia, v.33, n.2, p.463-470, 2004.

HENRIQUE, W.; SAMPAIO, A.A.M.; LEME, P.R. et al. Digestibilidade e balanço de nitrogênio em ovinos alimentados à base de rações com elevado teor de concentrado e níveis crescentes de polpa cítrica peletizada. Revista Brasileira de Zootecnia, v.32, n.6, p.2007-2015, 2003 (supl. 2).

LEIVA, E.; HALL, M.B.; VAN HENDRIX, H.H. Performance of dairy cattle fed citrus pulp or corn products as sources of neutral detergent - soluble carbohydrates. Journal of Dairy Science, v.83, n.12, p.2866-2875, 2000 .

LENG, R.A.; NOLAN, J.V. Nitrogen metabolism in the rumen. Journal of Dairy Science, v.67, n.5, p.1072-1089, 1984.

LOFGREEN, G.P. The estimation of total digestible nutrients from digestible organic matter. Journal of Animal Science, v.12, n.2, p.359-365, 1953.

NATIONAL RESEARCH COUNCIL - NRC. Nutrient requirements of small ruminants: sheep, goats, cervids, and New World camelids. Washington, D.C.: National Academic Press, 2007. 292p.

PALMQUIST, D.L.; CONRAD, H.R. Origin of plasma fatty acids in lactating cows fed high fat diets. Journal of Dairy Science, v.54, n.7, p.1025-1033, 1971.
PINHEIRO, A.D.; PRADO, I.N.; ALCALDE, C.R. et al. Efeitos dos níveis de substituição do milho pela polpa de citrus peletizada sobre a digestibilidade aparente em bovinos mestiços confinados. Acta Scientiarum, v.22, n.3, p.793-799, 2000.

POORE, M.H.; MOORE, J.A.; SWINGLE, R.S. et al. Response of lactating Holstein cows to diets varying in fiber source and ruminal starch degradability. Journal of Dairy Science, v.76, n.8, p.2235-2243, 1993.

PRADO, I.N.; PINHEIRO, A.D.; ALCALDE, C.R. et al. Níveis de substituição do milho pela polpa de citros peletizada sobre o desempenho e características de carcaça de bovinos mestiços confinados. Revista Brasileira de Zootecnia, v.29, n.6, p.2135-2141, 2000 (supl. 1).

RODRIGUES, G.H.; SUSIN, I.; PIRES, A.V. et al. Substituição do milho por polpa cítrica em rações com alta proporção de concentrado para cordeiros confinados. Ciência Rural, v.38, n.3, p.789-794, 2008.

SANTOS, F.A.P.; CARMOS, C.A.; MARTINEZ, J.C. et al. Desempenho de vacas em lactação recebendo dietas com diferentes teores de amido total, acrescidas ou não de levedura (Saccharomyces cerevisiae). Revista Brasileira de Zootecnia, v.35, n.4, p.1568-1575, 2006.

SILVA, L.D.F.; EZEQUIEL, J.M.B.; AZEVEDO, P.S. de et al. Digestão total e parcial de alguns componentes de dietas contendo diferentes níveis de casca de soja e fontes de nitrogênio, em bovinos. Revista Brasileira de Zootecnia, v.31, n. 3, p.1258-1268, 2002.

STATISTICAL ANALYSES SYSTEM - SAS. SAS systems for windows: version 9.1. Cary: SAS Institute, 2002. 525p.

TEDESCHI, L.O.; FOX, D.G.; PELL, A.N. et al. Development and evaluation of a tropical feed library for the Cornell net carbohydrate and protein system model. Scientia Agricola, v.59, n.1, p.1-18, 2002.

VAN SOEST, P.J.; ROBERTSON, J.B. LEWIS, B.A. Methods for dietary fiber, neutral detergent fiber, and nonstarch polysaccharides in relation to animal nutrition. Journal of Dairy Science, v.74, n.10, p.3583-3597, 1991.

WALDO, D.R. Symposium: Forage utilization by the lactating cow. Effect of forage quality on intake and forage concentrate interactions. Journal of Dairy Science, v.69, n.2, p.617-631, 1986.

WING, J.M.; VAN HORN, H.H.; SKLARE, S.D. et al. Effects of citrus molasses, distillers solubles and molasses on rumen parameters and lactation. Journal of Dairy Science, v.71, n.2, p.414-420, 1988. 